Check for updates

Cite this: RSC Adv., 2017, 7, 41788

Received 13th July 2017

Accepted 22nd August 2017

DOI: $10.1039 / \mathrm{c} 7 \mathrm{ra07711d}$

rsc.li/rsc-advances

\title{
Improving piezoelectric properties by controlling phase structure and crystal orientation
}

\begin{abstract}
Baihui Liu, (D) Xing Liu, (D) Peng Li, Feng Li, Bo Shen and Jiwei Zhai*
In this study, $\langle 001\rangle$-textured $(1-x) \mathrm{K}_{0.48} \mathrm{Na}_{0.52} \mathrm{Nb}_{0.96} \mathrm{Sb}_{0.04} \mathrm{O}_{3}-x \mathrm{Bi}_{0.50}\left(\mathrm{~K}_{0.48} \mathrm{Na}_{0.52}\right)_{0.50} \mathrm{Zr}_{0.50} \mathrm{Hf}_{0.50} \mathrm{O}_{3}$ [abbreviated as $(1-x)$ KNNS- $x$ BKNZH, $x=0.01-0.04$ ] lead-free ceramics were prepared by templated grain growth (TGG) method and sintered by a two-step process. Excellent longitudinal piezoelectric coefficient $d_{33}\left(434 \mathrm{pC} \mathrm{N}{ }^{-1}\right)$ and piezoelectric strain coefficient $d_{33}^{*}\left(722.5 \mathrm{pm} \mathrm{V}{ }^{-1}\right)$ are achieved in the textured 0.97KNNS-0.03BKNZH ceramics. The excellent piezoelectric properties can be ascribed to both the coexisting $\mathrm{R}-\mathrm{O}-\mathrm{T}$ multiphases and the $\langle 001\rangle$ crystal orientation. In addition, a high electromechanical coupling coefficient $k_{p}(\sim 73.6 \%)$ is attained in textured ceramics with $x=0.02$. The values of $d_{33}$ and $k_{\mathrm{p}}$ also display high thermal stability (with rate of change $< \pm 10 \%$ ) over $25-120{ }^{\circ} \mathrm{C}$ in textured ceramics with $x=0.03$ and 0.04 . Excellent comprehensive properties suggest that $\langle 001\rangle$ textured $(1-x)$ KNNS-xBKNZH ceramics are promising lead-free candidates for actuator and transducer applications.
\end{abstract}

\section{Introduction}

It is generally known that single crystals exhibit higher piezoelectric coefficients and coupling coefficients than do polycrystalline ceramics. ${ }^{1}$ Park and Shrout found that an ultrahigh piezoelectric coefficient $\left(d_{33}>2500 \mathrm{pC} \mathrm{N}^{-1}\right)$ and strain $(>0.6 \%)$ could be achieved in $\langle 001\rangle$-oriented rhombohedral $\mathrm{Pb}\left(\mathrm{Zn}_{1 / 3} \mathrm{Nb}_{2 / 3}\right)$ $\mathrm{O}_{3}-\mathrm{PbTiO}_{3}$ crystals, and this study has attracted numerous researchers to explore this class of materials. ${ }^{2}$ The excellent piezoelectric properties resulted from not only the designed composition close to the morphotropic phase boundary (MPB), but also the crystal orientation., ${ }^{3,4}$ Single crystals show a strong anisotropic nature, i.e., the piezoelectricity along certain directions is superior to that along other directions. ${ }^{5}$ Therefore, single crystals with optimum crystallographic cuts present ascendant piezoelectric responses compared with polycrystalline ceramics whose properties are the average over each grain. ${ }^{6-8}$ The Bridgman method is widely used in preparing large size ferroelectric single crystals, but many parts of final product have serious component segregation. ${ }^{9}$ This chemical heterogeneity may decrease the piezoelectric properties which are sensitive to composition and reduce the yield. Slow growth rate and low availability make single crystals in the market expensive.

The high cost of single crystals and low piezoelectric properties of polycrystalline ceramics calls for new materials which take the advantages of both. ${ }^{10}$ If the unordered grains of ceramics can orient along certain direction like single crystals

Functional Materials Research Laboratory, School of Materials Science \& Engineering, Tongji University, 4800 Caoan Road, Shanghai 201804, China. E-mail: apzhai@ tongji.edu.cn via controlling microstructure, the piezoelectric properties will be improved obviously. Ceramics with intensively aligned crystal axes are called "textured" ceramics. ${ }^{11}$ Textured piezoelectric material SbSI was first proposed by Okazaki in $1968,{ }^{12}$ and researchers extended this application to perovskitestructure materials in the late $1990 \mathrm{~s}^{13}$ Right now, textured lead-based ceramics have achieved greatly improved piezoelectric properties compared with their randomly oriented counterparts. Yan et al. have obtained excellent electromechanical coupling factors $\left(k_{31}=k_{\mathrm{h}}=0.60\right.$, and $\left.k_{1}=0.7\right),{ }^{14}$ giant piezoelectric voltage coefficient $\left(g_{33}=115 \times 10^{-3} \mathrm{Vm} \mathrm{N}^{-1}\right)^{15}$ and energy density $\left(d_{33} g_{33}=59180 \times 10^{-15} \mathrm{~m}^{2} \mathrm{~N}^{-1}\right)^{16}$ in $\mathrm{Pb}(\mathrm{Zr}$, Ti) $\mathrm{O}_{3}$ (PZT)-based textured ceramics. Lead is a kind of toxic heavy metals which are harmful to the human bodies, and lead also easy to volatilize at high temperature due to its low melting point. Consequently, lead-free ceramics become a research hotspot in recent years. Texture is also an effective method to improve the properties of lead-free ceramics. Using TGG method, textured $\mathrm{BaTiO}_{3}$ (BT)-based ceramics have obtained highly enhanced dielectric and piezoelectric properties. ${ }^{17-20}$ In 2004, Saito and his coworkers successfully prepared $\langle 001\rangle$ textured $\left(\mathrm{K}_{0.44} \mathrm{Na}_{0.52} \mathrm{Li}_{0.04}\right)\left(\mathrm{Nb}_{0.86} \mathrm{Ta}_{0.10} \mathrm{Sb}_{0.04}\right) \mathrm{O}_{3}$ (LF4) ceramics which displayed excellent piezoelectric responses $\left(d_{33}=\right.$ $416 \mathrm{pC} \mathrm{N}^{-1}, k_{\mathrm{p}}=0.61$ ) and could be comparable with PZT-based ceramics. ${ }^{21}$ After that, tape casting technology was widely used to prepare highly textured KNN-based ceramics and improved dielectric and piezoelectric properties were also achieved. ${ }^{22-25}$ However, it is worth noting that there has been no breakthrough in textured KNN-based ceramics since 2004. Piezoelectric coefficient $d_{33}$ of most textured KNN-based ceramics are in the range of $200-300 \mathrm{pC} \mathrm{N}^{-1}$, which is far below the industrial 
requirements. ${ }^{22,24}$ Therefore, more efforts should focus on textured KNN-based ceramics.

Two important points should be considered during the process of preparing textured ceramics: one is orientation degree, and the other is composition. ${ }^{10}$ Just like single crystals, highly textured KNN-based ceramics with compositions around polymorphic phase transition (PPT) usually exhibit better piezoresponse. According to the research of Zheng et al., both $\mathrm{Bi}_{0.5} \mathrm{Na}_{0.5} \mathrm{HfO}_{3}$ and $\mathrm{Bi}_{0.5} \mathrm{Na}_{0.5} \mathrm{ZrO}_{3}$ end members could increase the rhombohedral-orthorhombic phase transition temperature $\left(T_{\mathrm{R}-\mathrm{O}}\right)$, and decrease the orthorhombic-tetragonal phase transition temperature $\left(T_{\mathrm{O}-\mathrm{T}}\right)$ at the same time. Finally, the rhombohedral-tetragonal $(\mathrm{R}-\mathrm{T})$ phase boundary was constructed in KNN-based ceramics. ${ }^{26}$ Therefore, $\mathrm{Hf}$ and $\mathrm{Zr}$ ions were chosen as dopant to construct polymorphic phase boundaries in this work. $\langle 001\rangle$-textured $(1-x) \mathrm{K}_{0.48} \mathrm{Na}_{0.52} \mathrm{Nb}_{0.96} \mathrm{Sb}_{0.04} \mathrm{O}_{3}-x \mathrm{Bi}_{0.50^{-}}$ $\left(\mathrm{K}_{0.48} \mathrm{Na}_{0.52}\right)_{0.50} \mathrm{Zr}_{0.50} \mathrm{Hf}_{0.50} \mathrm{O}_{3}$ ceramics were prepared by TGG method using $3 \mathrm{~mol} \% \mathrm{NaNbO}_{3}(\mathrm{NN})$ templates. Our previous work showed that $3 \mathrm{~mol} \% \mathrm{NN}$ templates were suitable for preparing highly textured ceramics. ${ }^{27}$ The aim of this work is to interpret the relationship between BKNZH contents and phase structure, microstructure as well as piezoelectric, ferroelectric, dielectric properties of textured ceramics.

\section{Experimental procedure}

NN platelets were selected as template due to easier formation of anisotropic morphology and small lattice mismatch with matrix. NN templates were synthesized by two-step molten salt method through the following two procedures: first, synthesized bismuth layer-structured $\mathrm{Bi}_{2.5} \mathrm{Na}_{3.5} \mathrm{Nb}_{5} \mathrm{O}_{18}$ (BiNN5) precursors in air atmosphere by reacting $\mathrm{Bi}_{2} \mathrm{O}_{3}$ (99.975\%), $\mathrm{Nb}_{2} \mathrm{O}_{5}$ (99.9\%), $\mathrm{Na}_{2} \mathrm{CO}_{3}(99.95-100.05 \%)$ powders in $\mathrm{NaCl}(98 \%)$ molten salts at $1100{ }^{\circ} \mathrm{C}$ for $2 \mathrm{~h}$; second, produced monocrystalline plate-like NN templates in air atmosphere through a topochemical conversion reaction between BiNN5 and $\mathrm{Na}_{2} \mathrm{CO}_{3}$ powders in $\mathrm{NaCl}$ molten salts at $900{ }^{\circ} \mathrm{C}$ for $2 \mathrm{~h}$. The matrix powders were synthesized by conventional solid state reaction process in air atmosphere using $\mathrm{K}_{2} \mathrm{CO}_{3}(99 \%), \mathrm{Na}_{2} \mathrm{CO}_{3}$ (99.95-100.05\%), $\quad \mathrm{Nb}_{2} \mathrm{O}_{5}$ (99\%), $\quad \mathrm{Sb}_{2} \mathrm{O}_{3} \quad(99.998 \%), \quad \mathrm{Bi}_{2} \mathrm{O}_{3}$ (99.975\%), $\mathrm{ZrO}_{2}(99 \%)$ and $\mathrm{HfO}_{2}(99.9 \%)$ as the raw materials. For tape casting, homogeneous slurry containing the calcined matrix powders, $\mathrm{NN}$ templates, toluene, alcohol and binder was casted by a homemade tape casting machine. The dried tapes were cut, stacked, laminated at $70{ }^{\circ} \mathrm{C}$ under a pressure of $20 \mathrm{MPa}$ for $1 \mathrm{~h}$ to obtain green compacts. After burning off the organic matters in air atmosphere at $550{ }^{\circ} \mathrm{C}$ for $10 \mathrm{~h}$ with a heating rate of $1{ }^{\circ} \mathrm{C} \mathrm{min}^{-1}$, green compacts were sintered in air atmosphere by a two-step sintering process. The sintering procedure was programmed from room temperature to the firststep sintering temperature $\left(1190{ }^{\circ} \mathrm{C}\right)$ with a heating rate of $3{ }^{\circ} \mathrm{C} \mathrm{min}^{-1}$, then rapid cooled to the lower second-step sintering temperature $\left(1060-1090{ }^{\circ} \mathrm{C}\right)$ with a heating rate of $10^{\circ} \mathrm{C} \mathrm{min}^{-1}$ and held for $10 \mathrm{~h}$. The long holding time provided enough energy for growth of oriented grains and densification.

The phase structure was extracted from X-ray diffraction (XRD, MiniFlex 600, Rigaku, Japan; $\mathrm{Cu} \mathrm{K}_{\alpha}$ radiation; at an accelerating voltage of $40 \mathrm{kV}$ and an operating current of $25 \mathrm{~mA})$ and transmission electron microscope (TEM, CM200FEG, Philips, Netherlands; at an accelerating voltage of $200 \mathrm{kV}$ ). Lotgering factor $(f)$ was widely used to evaluate the degree of orientation for textured materials using the diffraction peak intensities of XRD patterns. The Lotgering factor was calculated by the following equations:

$$
\begin{aligned}
f & =\frac{p-p_{0}}{1-p_{0}} \\
p & =\frac{\sum I_{(00 l)}}{\sum I_{(h k l)}} \\
p_{0} & =\frac{\sum I_{0(00 l)}}{\sum I_{0(h k l)}}
\end{aligned}
$$

where $\sum I_{(00 l)}$ and $\sum I_{0(00 l)}$ was the summation of XRD peak intensities of all ( $00 l)$ peaks for textured and randomly oriented materials, respectively; $\sum I_{(h k l)}$ and $\sum I_{0(h k l)}$ was the summation of XRD peak intensities of all $(h k l)$ peaks for textured and randomly oriented materials, respectively. ${ }^{28}$ The Lotgering factor was calculated in a $2 \theta$ scan between $10-80^{\circ}$.

The cross-section microstructures of samples were observed by scanning electron microscopy (SEM, JSM-5510LV, Japan; Au coated; secondary electron mode at an accelerating voltage of 20 $\mathrm{kV})$. Polished samples with silver electrode were poled under a DC electric field of $15 \mathrm{kV} \mathrm{mm}^{-1}$, and then the piezoelectric constant $d_{33}$ was measured using a quasi-static $d_{33}$ meter (ZJ-6A, Institute of acoustics, China). Relative dielectric constant $\left(\varepsilon_{\mathrm{r}}\right)$ and loss tangent $(\tan \delta$ ) of virgin samples as a function of temperature were measured utilizing a precision LCR meter (E4980A, Agilent, USA) connected with a temperature controlled chamber. Planar electromechanical coupling factor $\left(k_{\mathrm{p}}\right)$ and phase angle $(\theta)$ of poled samples were tested by resonanceantiresonance method with an impedance analyzer (HP 4294A). The electric-field-induced polarization $(P-E)$ and strain $(S-E)$ measurements were carried out using a ferroelectric test system (Precision Premier II, Radiant Technologies Inc, Albuquerque, NM) connected with a miniature plane-mirror interferometer and the accessory laser interferometer vibrometer (SP-S 120/500, SIOS Mebtechnik GmnH, llmenau, Germany).

\section{Results and discussion}

Template plays significant role in TGG process. The degree of texture depends on the number, size, distribution of templates, and the orientation of textured grains depends on the initial orientation of templates..$^{10}$ Fig. 1 shows the XRD pattern, SEM and TEM images of NN templates synthesized by two-step molten salt method. It can be seen that NN templates possess a single phase perovskite structure and a high aspect ratio microstructure (average $15 \mu \mathrm{m}$ in length, $5 \mu \mathrm{m}$ in width and $1 \mu \mathrm{m}$ in thickness). Thus the templates can be mechanically oriented under an applied shear force given by the doctor blade. The intensity of (100) and (200) peaks in XRD patterns of NN templates are stronger than expected, indicating that the NN 

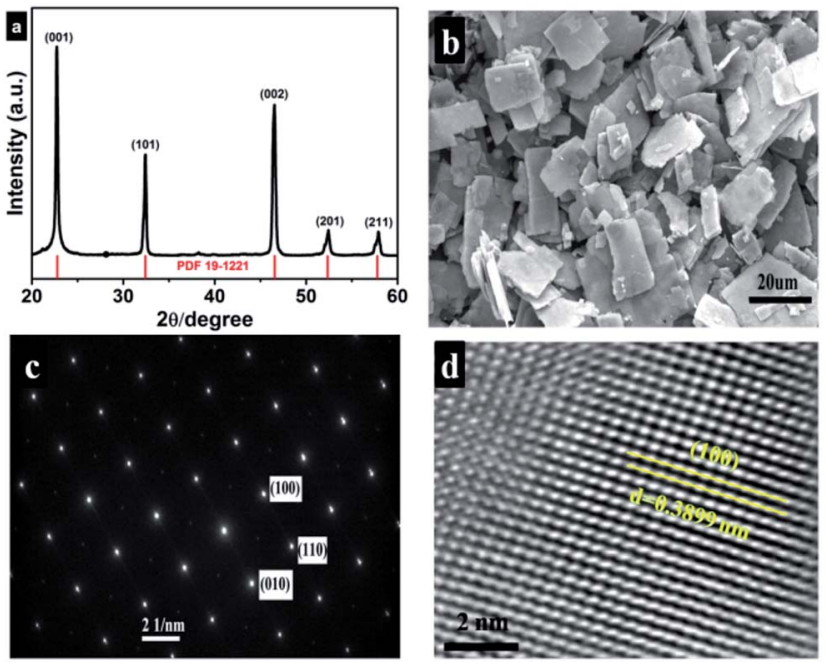

Fig. 1 (a) XRD pattern of NN templates; (b) SEM image of NN templates; (c) SAED of NN templates; (d) HRTEM of NN templates.

templates have $\langle 001\rangle$-preferred orientation. ${ }^{29}$ The results of selected area electron diffraction (SAED) for individual template reveal that NN templates are of single-crystal structure and possess an orientation along the [100] direction. The $d$ spacing $(0.3899 \mathrm{~nm})$ estimated from the lattice fringe also corresponds well to the [100] crystal direction. ${ }^{30}$

Fig. 2(a) shows the room-temperature XRD patterns of textured $(1-x)$ KNNS- $x$ BKNZH ceramics. All samples are pure perovskite structure which indicates that $\mathrm{Sb}^{5+}, \mathrm{Bi}^{3+}, \mathrm{Zr}^{4+}$ and $\mathrm{Hf}^{4+}$ have been completely incorporated into KNN lattice. It can be clearly seen that the relative intensities of (100) and (200) peaks are stronger than expected. Lotgering factor of textured ceramics with $x=0.01,0.02,0.03$ and 0.04 is $91.13 \%, 93.79 \%$, $90.51 \%$ and $89.16 \%$, respectively. The enhanced (100) and (200) peak intensities and high Lotgering factors reveal that $\langle 001\rangle$-preferred orientation has been achieved in textured $(1-x)$ KNNS- $x$ BKNZH ceramics. Fig. $2(b)$ exhibits the enlarged XRD patterns of $(002) /(200)$ peaks in the $2 \theta$ range of $44-47^{\circ}$. The shape of $(002) /(200)$ peaks changes apparently with the addition of BKNZH. The piezoelectric properties of KNN-based ceramics are closely bound up with phase structure which can be roughly confirmed by the ratio of (002) and (200) peak intensities $\left(I_{(002)} /\right.$ $I_{(200))} \cdot{ }^{31} I_{(002)} / I_{(200)}$ is equal to 2 for $O$ phase but decreases to 0.5 for T phase. Consequently, $I_{(002)} / I_{(200)}$ approaching to 1 implies the coexistence of $\mathrm{O}$ and $\mathrm{T}$ phase. $I_{(002)} / I_{(200)}$ of textured ceramics with $x=0.01$ and $x=0.02$ is 2.23 and 1.57 respectively, which signifies that $\mathrm{O}$ phase is formed. PPT not only changes with composition but also with temperature, therefore $\varepsilon_{\mathrm{r}}-T$ curves are used to trace the phase evolution. As shown in Fig. $1(\mathrm{c}), T_{\mathrm{R}-\mathrm{O}}\left(-40.2^{\circ} \mathrm{C}\right)$ and $T_{\mathrm{O}-\mathrm{T}}\left(128^{\circ} \mathrm{C}\right)$ of textured ceramics with $x=0.02$ are both far away from room temperature, which indicates that textured ceramics with $x=0.02$ are of $O$ phase at room temperature. With increasing addition of $\mathrm{BKNZH}, T_{\mathrm{O}-\mathrm{T}}$ of textured ceramics gradually decreases from $128{ }^{\circ} \mathrm{C}$ to $30.8{ }^{\circ} \mathrm{C}$, and $T_{\mathrm{R}-\mathrm{O}}$ gradually increases at the same time. The simultaneous shift of $T_{\mathrm{R}-\mathrm{O}}$ to the high temperature direction and $T_{\mathrm{O}-\mathrm{T}}$
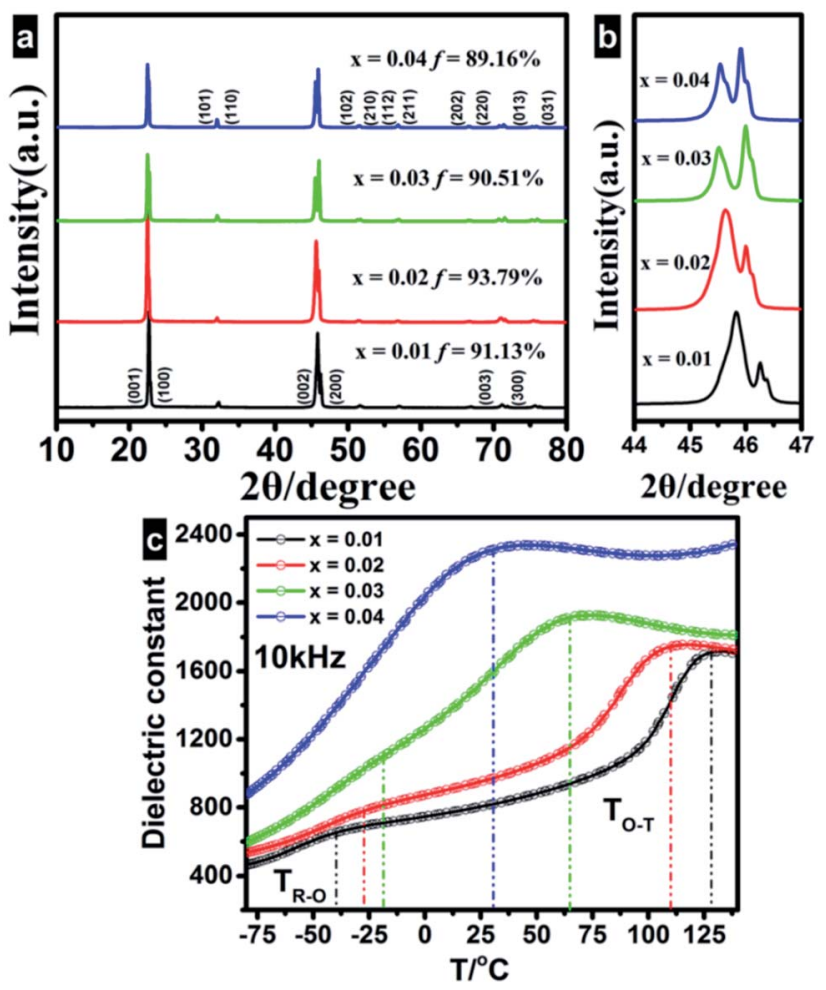

Fig. 2 (a) XRD patterns of textured $(1-x)$ KNNS- $x$ BKNZH ceramics; (b) enlarged XRD patterns in the range of $2 \theta$ from $44^{\circ}$ to $47^{\circ}$; (c) $\varepsilon_{r}-T$ curves measured from $-80^{\circ} \mathrm{C}$ to $140{ }^{\circ} \mathrm{C}$ at $10 \mathrm{kHz}$.

to the low temperature direction compresses the $\mathrm{O}$ phase zone. Finally there is only one obvious dielectric peak for the textured ceramics with $x=0.04$ near the room temperature, which manifests that R-T phase boundaries is formed by modifying BKNZH content. ${ }^{32} I_{(002)} / I_{(200)}(0.72)$ of textured ceramics with $x=0.03$ decreases apparently compared with that of textured ceramics with $x=0.02$, which indicates that phase structure of textured $0.97 \mathrm{KNNS}-0.03 \mathrm{BKNZH}$ ceramics is greatly changed. As the middle phase between $\mathrm{O}$ phase of textured $0.98 \mathrm{KNNS}-0.02 \mathrm{BKNZH}$ ceramics and R-T phase of textured 0.96KNNS-0.04BKNZH ceramics, the phase of textured $0.97 \mathrm{KNNS}-0.03 \mathrm{BKNZH}$ ceramics is believed to be a mixed one. While the specific phase composition of textured ceramics with $x=0.03$ needs to be further confirmed by its corresponding $\varepsilon_{\mathrm{r}}-T$ curves. $T_{\mathrm{R}-\mathrm{O}}\left(-18.5^{\circ} \mathrm{C}\right)$ and $T_{\mathrm{O}-\mathrm{T}}\left(64.8^{\circ} \mathrm{C}\right)$ of textured ceramics with $x=0.03$ are both near room temperature, which indicates that $\mathrm{R}-\mathrm{O}$ phase and $\mathrm{O}-\mathrm{T}$ phase are coexistent at room-temperature. Therefore, textured $0.97 \mathrm{KNNS}-0.03 \mathrm{BKNZH}$ ceramics are of $\mathrm{R}-\mathrm{O}-\mathrm{T}$ phase. In addition, similar phenomenon could be observed in $\mathrm{R}-\mathrm{O}-\mathrm{T}$ phasecoexistent $\quad 0.97\left(\mathrm{~K}_{0.4} \mathrm{Na}_{0.6}\right)\left(\mathrm{Nb}_{0.96} \mathrm{Sb}_{0.04}\right) \mathrm{O}_{3}-0.03 \mathrm{Bi}_{0.5} \mathrm{~K}_{0.5} \mathrm{Zr}_{0.9^{-}}$ $\mathrm{Sn}_{0.1} \mathrm{O}_{3} \quad$ ceramics and $0.97\left(\mathrm{~K}_{0.52} \mathrm{Na}_{0.48}\right)\left(\mathrm{Nb}_{0.95} \mathrm{Sb}_{0.05}\right) \mathrm{O}_{3^{-}}$ $0.03 \mathrm{Bi}_{0.5}\left(\mathrm{~K}_{0.18} \mathrm{Na}_{0.82}\right)_{0.5} \mathrm{ZrO}_{3}$ ceramics. $^{32,33}$ According to the results of XRD patterns and $\varepsilon_{\mathrm{r}}-T$ curves, the phase evolution of textured $(1-x)$ KNNS- $x$ BKNZH ceramics at room temperature can be identified: when $x \leq 0.02$, $O$ phase is formed; when $x=$ 0.03 , the ceramics are of $\mathrm{R}-\mathrm{O}-\mathrm{T}$ coexistent phase; when $x=$ $0.04, \mathrm{R}-\mathrm{T}$ coexistent phase is formed. 
Fig. 3 displays the cross-section SEM images of textured $(1-x)$ KNNS- $x$ BKNZH ceramics and element mapping of the surface in textured $0.99 \mathrm{KNNS}-0.01 \mathrm{BKNZH}$ ceramics. It can be seen from Fig. 3(a) that the grains stick together like a whole "stone" when $x \leq 0.03$. For textured ceramics with $x=0.04$, bimodal grain size distributions can be observed, i.e., $2 \mu \mathrm{m}$ sized minor grains fill the gaps between $20 \mu \mathrm{m}$ sized large grains. These results manifest that liquid phase is present due to the high first-step sintering temperature $\left(1190{ }^{\circ} \mathrm{C}\right) .{ }^{34,35}$ The low-porosity microstructure suggests that two-step sintering method is effective in eliminating pores and improving density of textured ceramics. ${ }^{36}$ As shown in Fig. 3(b), O, Na, K, Nb, Sb, $\mathrm{Bi}, \mathrm{Zr}$, and $\mathrm{Hf}$ elements are evenly distributed in textured 0.99KNNS-0.01BKNZH ceramics.

The temperature dependence of $\varepsilon_{\mathrm{r}}$ and $\tan \delta$ for textured $(1-x)$ KNNS- $x$ BKNZH ceramics measured at $10 \mathrm{kHz}$ from $35^{\circ} \mathrm{C}$ to $480{ }^{\circ} \mathrm{C}$ are demonstrated in Fig. 4(a). It can be seen that the Curie temperature $\left(T_{\mathrm{c}}\right)$ of textured samples monotonically decreases from $310.2{ }^{\circ} \mathrm{C}$ to $273.0^{\circ} \mathrm{C}$ with increasing addition of BKNZH. $T_{\mathrm{O}-\mathrm{T}}$ also decreases monotonically which is corresponding with the results of Fig. 1(c). The values of $\varepsilon_{\mathrm{r}}$ for textured samples with $x=0.03$ and 0.04 are both exceeding 2000 at $35{ }^{\circ} \mathrm{C}$, suggesting that the addition of BKNZH can increase $\varepsilon_{\mathrm{r}}{ }^{37}$ The $\tan \delta$ slightly increases with increase of $\mathrm{BKNZH}$ content at $35{ }^{\circ} \mathrm{C}$, but values of $\tan \delta$ for textured samples are all below 0.03 . Textured ceramics have no significant conductivity when temperature below $T_{\mathrm{c}}$, while $\tan \delta$ increases quickly when temperature above $T_{\mathrm{c}}$ due to the thermal activation of conducting ions. In order to clearly address the phase evolution of textured ceramics, a phase diagram is drawn in Fig. 4 (b). $T_{\mathrm{R}-\mathrm{O}}$ is related to $\mathrm{R}$ and $\mathrm{O}$ phase transition; $T_{\mathrm{O}-\mathrm{T}}$ is connected with $\mathrm{O}$ and $\mathrm{T}$ phase transition; and Curie temperature $T_{\mathrm{c}}$ is tetragonal and cubic phase transition temperature. ${ }^{33}$ It can be clearly seen that the simultaneous shift of $T_{\mathrm{R}-\mathrm{O}}$ and $T_{\mathrm{O}-\mathrm{T}}$ compresses the $\mathrm{O}$ phase zone, and finally forms $\mathrm{R}-\mathrm{O}-\mathrm{T}$ and $\mathrm{R}-\mathrm{T}$ coexistent phase in ceramics with $x=$ 0.03 and $x=0.04$ in the room temperature zone, respectively. ${ }^{38}$ $T_{\mathrm{c}}$ gradually shifts to the low temperature direction with increasing addition of BKNZH.

The polarization hysteresis $(P-E)$ loops of textured $(1-x)$ KNNS- $x$ BKNZH ceramics measured at $10 \mathrm{~Hz}$ are displayed in Fig. 5(a). A typical well-saturated ferroelectric hysteresis loops can be observed in all samples, which indicates that textured $(1-x)$ KNNS- $x$ BKNZH ceramics possess good ferroelectric properties. ${ }^{39}$ Typically butterfly shaped bipolar strain curves can be observed in all textured ceramics and depicted in Fig. 5(b). To fully understand the ferroelectric properties of textured ceramics, remnant polarization $\left(P_{\mathrm{r}}\right)$, coercive field $\left(E_{\mathrm{c}}\right)$ and negative strain $\left(S_{\text {neg }}\right)$ as a function of $x$ are plotted in Fig. 5(c). $P_{\mathrm{r}}$ increases with increase of $x$, reaching the maximum value $\left(30.3 \mu \mathrm{C} \mathrm{cm}^{-2}\right)$ at $x=0.03$, and then declines to $27.5 \mu \mathrm{C} \mathrm{cm}^{-2}$ at $x=0.04$. The largest $E_{\mathrm{c}}\left(18.65 \mathrm{kV} \mathrm{cm}^{-1}\right)$ is obtained in textured ceramics with $x=0.02$, further increase of BKNZH content will decreases $E_{\mathrm{c}}$ to $15.57 \mathrm{kV} \mathrm{cm}^{-1}$ at $x=0.04$. Ferroelectric properties of textured ceramics with $0.03 \leq x \leq 0.04$ are promoted, which is reflected on the reduced $E_{\mathrm{c}}$ and enhanced $P_{\mathrm{r}}$. The negative strain $\left(S_{\text {neg }}\right)$ has similar change trend with $P_{\mathrm{r}}$, and also reaches the maximum value $(0.161 \%)$ at $x=0.03$. The magnitude of $S_{\text {neg }}$ is associated with the competitions between $180^{\circ}$ and non- $180^{\circ}$ ferroelectric domains switching. The more non$180^{\circ}$ domain switching, the greater $S_{\text {neg }}$ is. It also represents the reversible domain switching of piezoelectric ceramics, which can be regarded as the ferroelectricity contribution. So the improved $S_{\text {neg }}$ also implies enhanced ferroelectricity. ${ }^{40}$
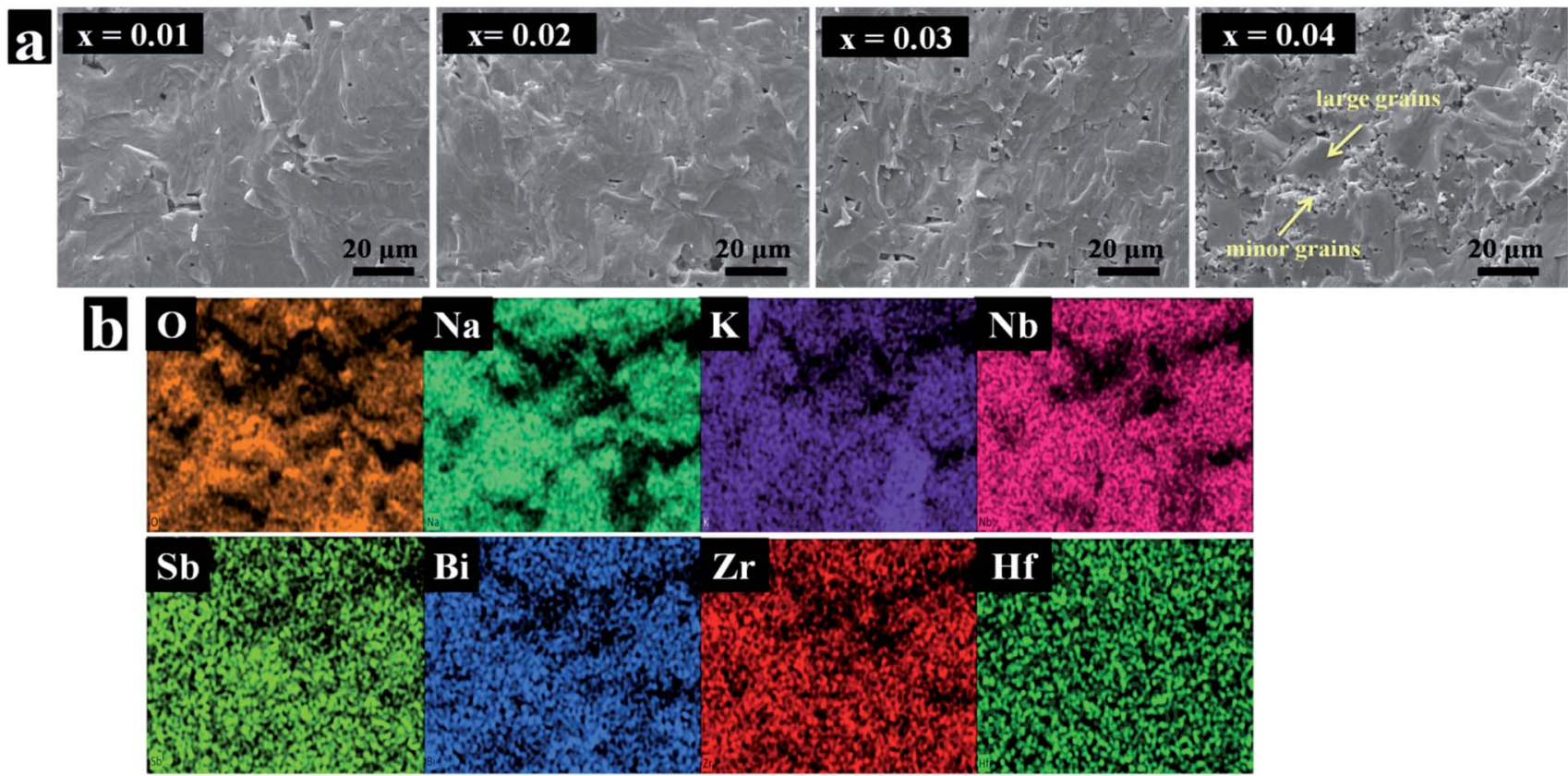

Fig. 3 (a) Cross-section SEM images of textured $(1-x)$ KNNS-xBKNZH ceramics; (b) element mapping of the surface in textured $0.99 K N N S-$ $0.01 \mathrm{BKNZH}$ ceramics. 

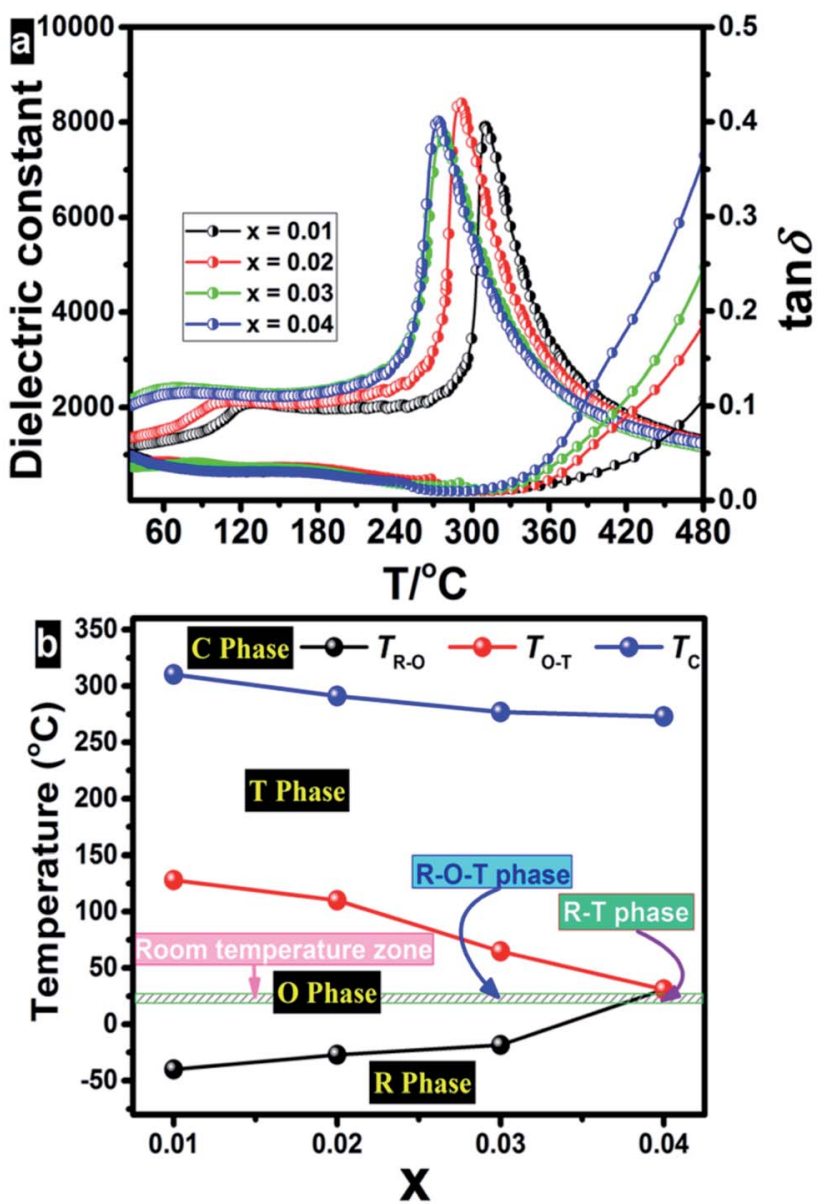

Fig. 4 (a) $\varepsilon_{\mathrm{r}}-T$ and $\tan \delta-T$ curves of textured $(1-x)$ KNNS- $x$ BKNZH ceramics measured from $35{ }^{\circ} \mathrm{C}$ to $480{ }^{\circ} \mathrm{C}$; (b) phase diagram of textured ceramics as a function of $x$.

The electric-field-induced unipolar strain curves and corresponding piezoelectric constant $d_{33}^{*}\left(S_{\max } / E_{\max }\right)$ are displayed in Fig. 6(a) and (b), respectively. The electric-field-induced strain of textured 0.97KNNS-0.03BKNZH ceramics reaches $0.145 \%$ under an electric field of $20 \mathrm{kV} \mathrm{cm}{ }^{-1}$, which satisfies the requirements of piezoelectric ceramics used for actuators (normally $0.1-0.15 \%$ at the same electric field). ${ }^{41} d_{33}^{*}$ of textured ceramics with $x=0.01$ is $413.3 \mathrm{pm} \mathrm{V}^{-1}$, and increases initially with increasing addition of BKNZH, then decreases when $x$ exceeding 0.03 . The maximum $d_{33}^{*}\left(722.5 \mathrm{pm} \mathrm{V}^{-1}\right)$ obtained in textured ceramics with $x=0.03$ can be comparable with randomly oriented PZT ceramics $\left(d_{33}^{*} \sim 500-750 \mathrm{pm} \mathrm{V}^{-1}\right)$ for actuators. The super piezoelectric properties of textured 0.97KNNS-0.03BKNZH ceramics can be attributed to its multiphase coexistent state and $\langle 001\rangle$ crystal orientation. The piezoresponse of ceramics is tightly associated with phase structure. The addition of BKNZH shifts $T_{\mathrm{R}-\mathrm{O}}$ to the high temperature direction and $T_{\mathrm{O}-\mathrm{T}}$ to the low temperature direction at the same time, and builds $\mathrm{R}-\mathrm{O}-\mathrm{T}$ coexistent phase for textured ceramics with $x=0.03$ and $\mathrm{R}-\mathrm{T}$ coexistent phase at $x=$ 0.04 at room temperature. ${ }^{42}$ The multiphase coexistence is a metastable thermodynamic status, and the polarization switching will become easier as the polarization directions increase. Thus the total spontaneous polarization $\left(P_{\mathrm{s}}\right)$ will increase, which leads to improved piezoresponse. ${ }^{43}$ Compared with $\mathrm{R}-\mathrm{T}$ phase boundary, the appearance of intermediate phase (i.e., $\mathrm{O}$ phase) in $\mathrm{R}-\mathrm{T}$ coexistent phase is more efficient in enhancing piezoelectric properties. The reasons why $\mathrm{R}-\mathrm{O}-\mathrm{T}$ phase is more efficient in enhancing piezoelectric properties are as follows: (i) R-O-T phase boundary can be regarded as the alliance of $\mathrm{R}-\mathrm{O}$ and $\mathrm{O}-\mathrm{T}$ phase boundaries, and more polarization directions can be found in it; ${ }^{44}$ (ii) as shown in Fig. 6(c), the $\langle 001\rangle$-oriented orthorhombic single crystals has four equivalent domains and a $\theta$ of $45.0^{\circ}$ when apply an electric field along [001] direction, while the $\langle 001\rangle$-oriented rhombohedral single crystals has four equivalent domains and a $\theta$ of $54.7^{\circ}$. It is expected that if the number of equivalent domains is the same, the smaller angle $\theta$ can cause better piezoelectric properties. Therefore, the appearance of $\mathrm{O}$ phase in $\langle 001\rangle$-textured ceramics is very important for obtaining improved piezoelectric performance when apply the electric field along the [001] directions. ${ }^{45}$

For high performance medical transducer application, $k_{\mathrm{p}}$ is an important parameter which is associated with the useable bandwidth of transducers. Piezoelectric constant $d_{33}$ is often used to present the piezoelectricity of ceramics. Fig. 7(a)
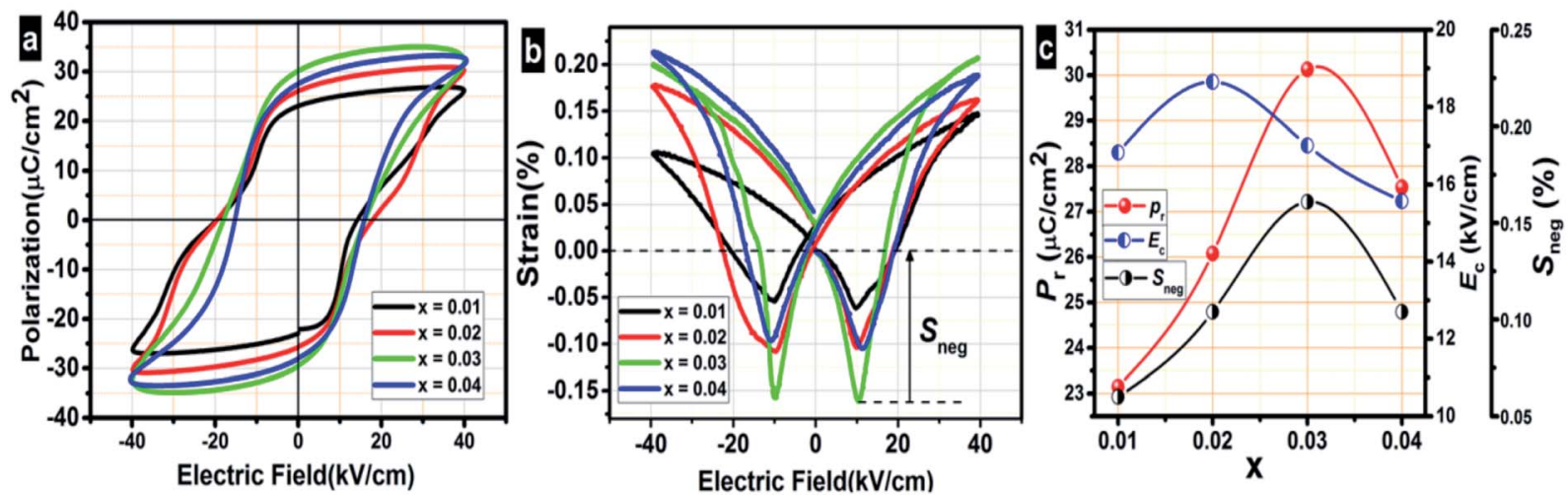

Fig. 5 (a) $P-E$ hysteresis loops of textured $(1-x)$ KNNS-xBKNZH ceramics measured at $10 \mathrm{~Hz}$; (b) bipolar $S-E$ curves measured at $10 \mathrm{~Hz}$; (c) composition dependence of $P_{\mathrm{r}}, E_{\mathrm{c}}$ and $S_{\text {neg. }}$. 

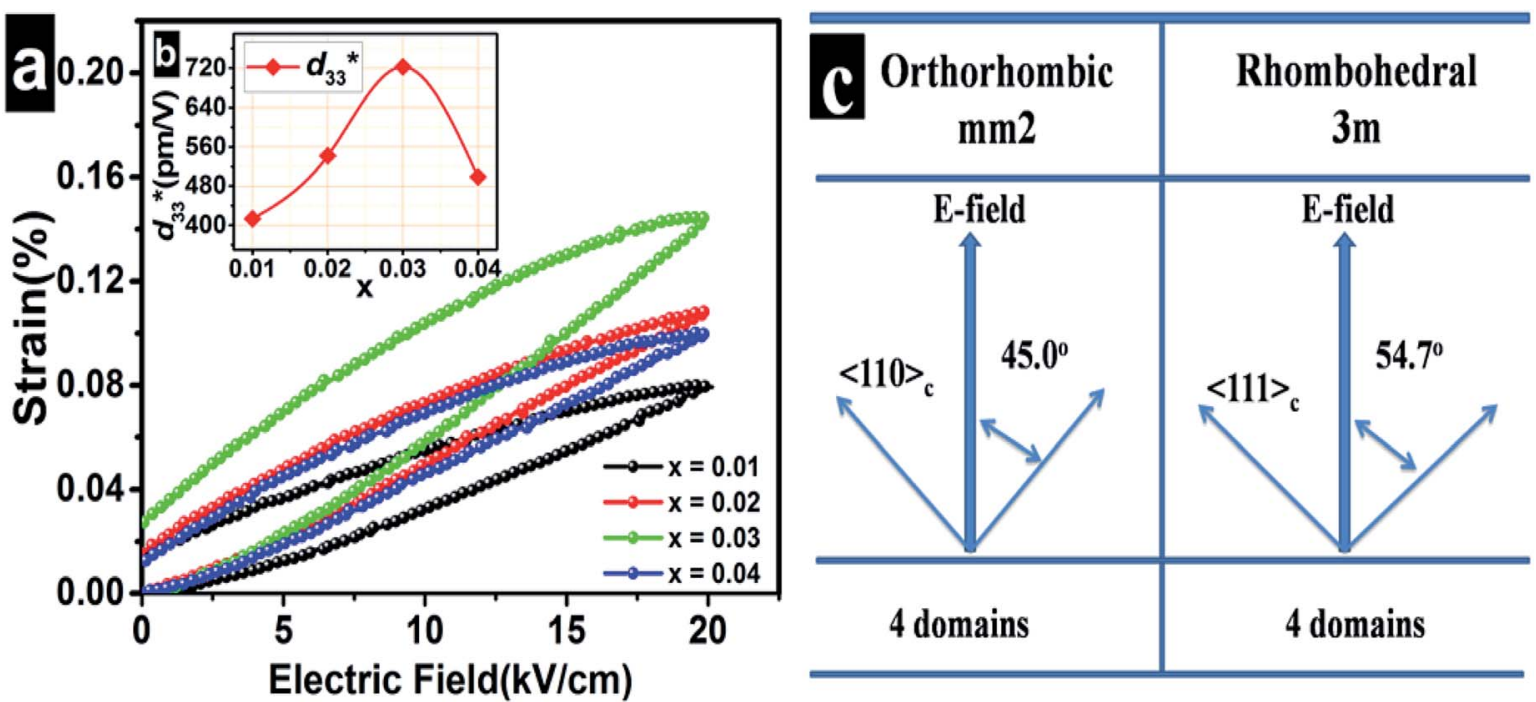

Fig. 6 (a) Unipolar S-E curves of textured $(1-x)$ KNNS-xBKNZH ceramics under an electric field of $20 \mathrm{kV} \mathrm{cm}^{-1}$; inset (b) $d_{33}^{*}$ with variations of $x$; (c) expected domain configurations for the $\langle 001\rangle$-oriented orthorhombic and rhombohedral single crystals under an electric field along [001] direction.

shows the composition dependence of $k_{\mathrm{p}}$ and $d_{33}$ for textured $(1-x)$ KNNS- $x$ BKNZH ceramics. The values of $k_{\mathrm{p}}$ for textured ceramics all exceed $55 \%$ which is a high value compared with the majority reports of KNN-based ceramics. The maximum $k_{\mathrm{p}}(\sim 73.6 \%)$ obtained in textured ceramics with $x=0.02$ is larger than that of textured LF4 ceramics. $^{21}$ Texture is an effective method to improve $k_{\mathrm{p}}$. According to Chang's report, $k_{\mathrm{p}}$ of textured $\left(\mathrm{K}_{0.5} \mathrm{Na}_{0.5}\right)_{0.98} \mathrm{Li}_{0.02} \mathrm{NbO}_{3}$ ceramics could reach $63 \%$, which is 1.5 times higher than its randomly oriented counterparts. ${ }^{46} d_{33}$ of textured ceramics has similar variation trend like $d_{33}^{*}$ and $P_{\mathrm{r}}$, and also reaches the maximum value $\left(434 \mathrm{pC} \mathrm{N}^{-1}\right.$ ) at $x=0.03$. Giant $d_{33}$ is derived from the texture technique and designed phase structured. The doping of BKNZH builds R-O-T coexistent phase at room temperature.
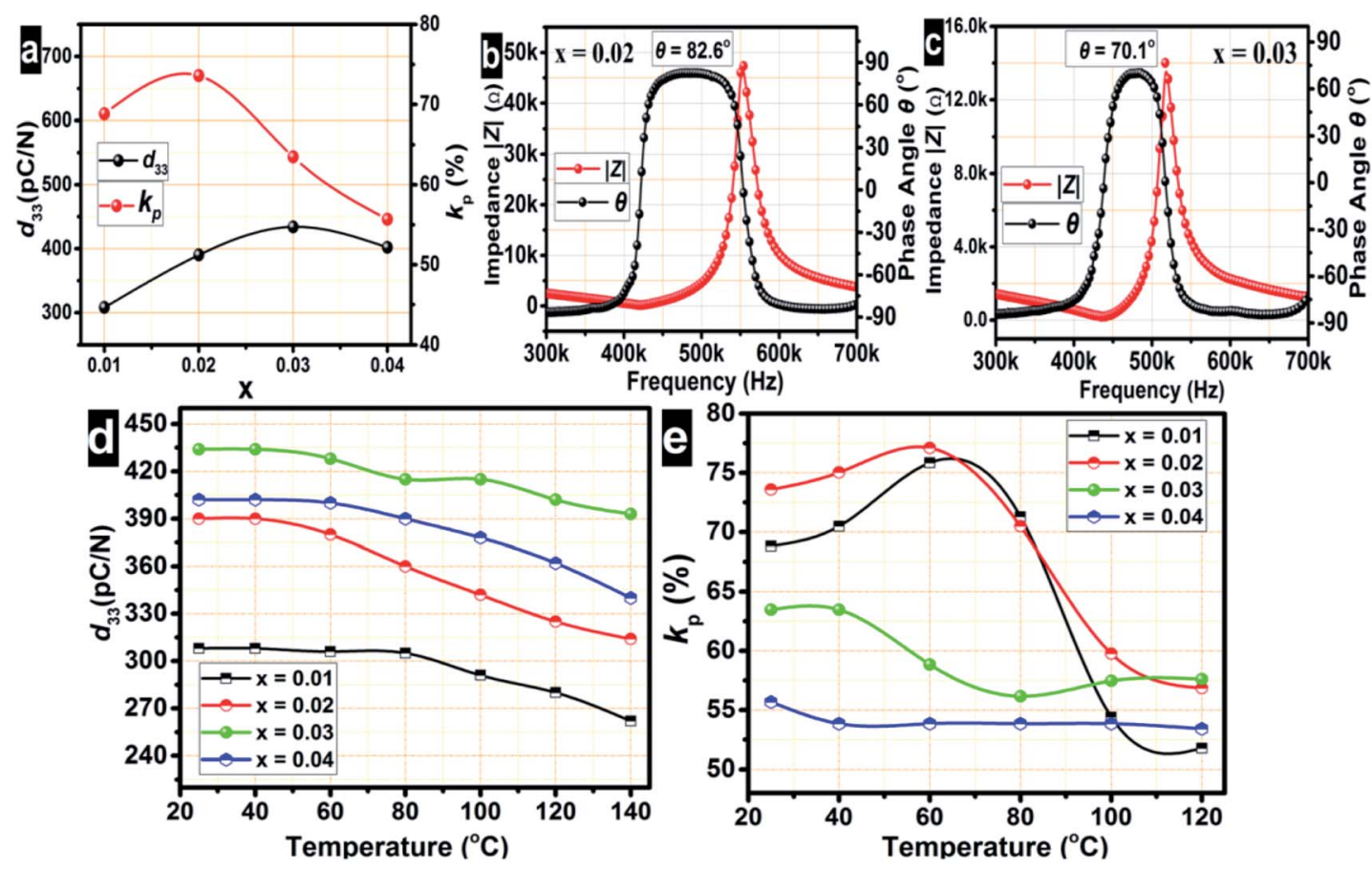

Fig. 7 (a) Composition dependence of $d_{33}$ and $k_{p}$ for textured $(1-x)$ KNNS-xBKNZH ceramics; frequency dependence of impedance $Z$ and phase angle $\theta$ for textured ceramics with (b) $x=0.02$ and (c) $x=0.03$; (d) $d_{33}$ values as a function of temperature; (e) $k_{\mathrm{p}}$ values as a function of temperature. 
Therefore enhanced piezoelectric properties can be achieved in textured $0.97 \mathrm{KNNS}-0.03 \mathrm{BKNZH}$ ceramics. Fig. 7 (b) and (c) plot the frequency dependence of impedance $Z$ and phase angle $\theta$ for textured ceramics with $x=0.02$ and $x=0.03$ as representatives, respectively. Textured ceramics all possess high phase angle which manifests that it is easier to pole these textured ceramics to an optimum state. ${ }^{47}$ For real industrial application, temperature stability is also an important consideration. ${ }^{48}$ The temperature dependence of $d_{33}$ and $k_{\mathrm{p}}$ for textured ceramics are demonstrated in Fig. $7(\mathrm{~d})$ and (e), respectively. With increase of temperature, $d_{33}$ of all samples decreases gradually. But the decrease of $d_{33}$ values are less than $10 \%$ relative to their room-temperature value at $120{ }^{\circ} \mathrm{C}$, which suggests that temperatureinsensitive $d_{33}$ can be obtained in textured $(1-x)$ KNNS$x$ BKNZH ceramics. $k_{\mathrm{p}}$ of textured ceramics with $x=0.01$ and 0.02 increase initially, reaching the maximum values at $60^{\circ} \mathrm{C}$, and then dramatically decline to the values which lower than $90 \%$ of their room-temperature value at $100{ }^{\circ} \mathrm{C}$. However, $k_{\mathrm{p}}$ of textured ceramics with $x=0.03$ and 0.04 change slightly with increase of temperature. In conclusion, textured ceramics with $x=0.03$ and 0.04 show temperatureinsensitive $d_{33}$ and $k_{\mathrm{p}}$.

\section{Conclusions}

In summary, $\langle 001\rangle$-textured $(1-x)$ KNNS- $x$ BKNZH $(x=0.01-$ $0.04)$ ceramics display dramatically improved piezoelectric properties. The addition of BKNZH builds $\mathrm{R}-\mathrm{O}-\mathrm{T}$ coexistent phase in textured ceramics with $x=0.03$ and $\mathrm{R}-\mathrm{T}$ phase in textured ceramics with $x=0.04$ at room temperature. The thermodynamic condition of $\mathrm{R}-\mathrm{O}-\mathrm{T}$ phase is metastable, thus the total $P_{\mathrm{s}}$ will increase, which leads to improved piezoresponse. The high Lotgering factors reveal that textured ceramics are of $\langle 001\rangle$-preferred orientation. Therefore, excellent $d_{33}$ $\left(434 \mathrm{pC} \mathrm{N}^{-1}\right)$ and $d_{33}^{*}\left(722.5 \mathrm{pm} \mathrm{V}^{-1}\right)$ can be achieved in textured ceramics with $x=0.03$. All textured ceramics exhibit good $k_{\mathrm{p}}$ $(>55 \%)$ and the maximum value $(\sim 73.6 \%)$ obtained in ceramics with $x=0.02$ is higher than that of textured LF4 ceramics. In addition, textured ceramics with $x=0.03$ and 0.04 show temperature-insensitive $d_{33}$ and $k_{\mathrm{p}}$ whose change rate are less than $\pm 10 \%$ from $25{ }^{\circ} \mathrm{C}$ to $120{ }^{\circ} \mathrm{C}$. These outstanding properties suggest that the $\langle 001\rangle$-textured $(1-x)$ KNNS- $x$ BKNZH ceramics are promising lead-free piezoelectric materials for transducer and actuator applications.

\section{Conflicts of interest}

There are no conflicts to declare.

\section{Acknowledgements}

The authors would like to acknowledge the National Natural Science Foundation of China under grant No. 51332003 and 51372171.

\section{Notes and references}

1 H. Liu, P. Veber, J. Koruza, D. Rytz, M. Josse, J. Rödel and M. Maglione, CrystEngComm, 2016, 18, 2081-2088.

2 S. E. Park and T. R. Shrout, J. Appl. Phys., 1997, 82, 18041811.

3 T. R. Shrout and S. J. Zhang, J. Electroceram., 2007, 19, 113126.

4 S. Zhang and F. Li, J. Appl. Phys., 2012, 111, 031301.

5 S. E. Park and T. R. Shrout, IEEE Trans. Ultrason. Eng., 1997, 44, 1140-1147.

6 X. Du, J. Zheng, U. Belegundu and K. Uchino, Appl. Phys. Lett., 1998, 72, 2421-2423.

7 P. W. Rehrig, G. L. Messing and S. Trolier-McKinstry, J. Am. Ceram. Soc., 2000, 83, 2654-2660.

8 K. Nakamura and Y. Kawamura, IEEE Trans. Ultrason. Eng., 2000, 47, 750-755.

9 H. Luo, G. Xu, H. Xu, P. Wang and Z. Yin, Jpn. J. Appl. Phys., Part 1, 2000, 39, 5581-5585.

10 G. L. Messing, S. Trolier-McKinstry, E. M. Sabolsky, C. Duran, S. Kwon, B. Brahmaroutu, P. Park, H. Yilmaz, P. W. Rehrig, K. B. Eitel, E. Suvaci, M. Seabaugh and K. S. Oh, Crit. Rev. Solid State Mater. Sci., 2004, 29, 45-96.

11 T. Kimura, J. Ceram. Soc. Jpn., 2006, 114, 15-25.

12 K. Okazaki and S. Narushima, J. Ceram. Soc. Jpn., 1968, 76. 13 T. Toshihiko, J. Korean Phys. Soc., 1998, 32, S1217-S1220.

14 Y. Yan, Y. Zhou and S. Priya, Appl. Phys. Lett., 2014, 104, 012910.

15 Y. Yan, J. E. Zhou, D. Maurya, Y. U. Wang and S. Priya, Nat. Commun., 2016, 7, 13089.

16 Y. Yan, K. H. Cho, D. Maurya, A. Kumar, S. Kalinin, A. Khachaturyan and S. Priya, Appl. Phys. Lett., 2013, 102, 042903.

17 E. M. Sabolsky, L. Maldonado, M. M. Seabaugh and S. L. Swartz, J. Electroceram., 2010, 25, 77-84.

18 W. Meier, K. E. Meyer, D. F. S. Gallis, M. A. Blea-Kirby, J. Roth, D. Felman, T. Breuer, G. J. Dension, F. J. Zutavern, W. Huebner and G. L. Brennecka, J. Am. Ceram. Soc., 2016, 99, 922-929.

19 S. H. Hong, S. Trolier-McKinstry and G. L. Messing, J. Am. Ceram. Soc., 2000, 83, 113-118.

20 H. Xue and Z. Xiong, J. Alloys Compd., 2009, 467, 338-341.

21 Y. Saito, H. Takao, T. Tani, T. Nonoyama, K. Takatori, T. Homma, T. Nagaya and M. Nakamura, Nature, 2004, 432, 84-87.

22 Y. Chang, S. F. Poterala, Z. Yang, S. Trolier-McKinstry and G. L. Messing, J. Mater. Res., 2011, 25, 687-694.

23 A. B. Haugen, G. H. Olsen, F. Madaro, M. I. Morozov, G. Tutuncu, J. L. Jones, T. Grande and M. A. Einarsrud, J. Am. Ceram. Soc., 2014, 97, 3818-3825.

24 T. Soller, R. Bathelt, K. Benkert, H. Bodinger and C. Schuh, J. Korean Phys. Soc., 2010, 57, 942-946.

25 H. Takao, Y. Saito, Y. Aoki and K. Horibuchi, J. Am. Ceram. Soc., 2006, 89, 1951-1956.

26 T. Zheng, J. Wu, D. Xiao, J. Zhu, X. Wang and X. Lou, ACS Appl. Mater. Interfaces, 2015, 7, 20332-20341. 
27 B. Liu, P. Li, B. Shen, J. Zhai, Y. Zhang, F. Li and X. Liu, Ceram. Interfaces, 2017, 43, 8004-8009.

28 F. K. Lotgering, J. Inorg. Nucl. Chem., 1959, 9, 113-123.

29 W. Bai, D. Chen, P. Zheng, J. Xi, Y. Zhou, B. Shen, J. Zhai and Z. Ji, J. Eur. Ceram. Soc., 2017, 37, 2591-2604.

30 S. Xu, J. F. Li and D. Viehland, J. Am. Ceram. Soc., 2011, 94, 3812-3818.

31 M. H. Zhang, K. Wang, J. S. Zhou, J. J. Zhou, X. Chu, X. Lv, J. Wu and J. F. Li, Acta Mater., 2017, 122, 344-351.

32 X. Wang, J. Wu, D. Xiao, J. Zhu, X. Cheng, T. Zheng, B. Zhang, X. Lou and X. Wang, J. Am. Chem. Soc., 2014, 136, 2905-2910.

33 T. Zheng, J. Wu, D. Xiao, J. Zhu, X. Wang, L. Xin and X. Lou, ACS Appl. Mater. Interfaces, 2015, 7, 5927-5937.

34 J. Hao, W. Bai, B. Shen and J. Zhai, J. Alloys Compd., 2012, 534, 13-19.

35 B. Qu, H. Du, Z. Yang, Q. Liu and T. Liu, RSC Adv., 2016, 6, 34381-34389.

36 J. Fang, X. Wang, Z. Tian, C. Zhong, L. Li and R. Zuo, J. Am. Ceram. Soc., 2010, 93, 3552-3555.

37 M. Matsubara, T. Yamaguchi, W. Sakamoto, K. Kikuta, T. Yogo and S. I. Hirano, J. Am. Ceram. Soc., 2005, 88, 1190-1196.

38 Z. Tan, J. Xing, L. Jiang, L. Sun, J. Wu, W. Zhang, D. Xiao and J. Zhu, RSC Adv., 2016, 6, 6983-6989.
39 H. Tao and J. Wu, J. Eur. Ceram. Soc., 2016, 36, 1605-1612.

40 M. H. Zhang, K. Wang, Y. J. Du, G. Dai, W. Sun, G. Li, D. Hu, H. C. Thong, C. Zhao, X. Q. Xi, Z. X. Yue and J. F. Li, J. Am. Chem. Soc., 2017, 139, 3889-3895.

41 C. A. Randall, A. Kelnberger, G. Y. Yang, R. E. Eltel and T. R. Shrout, J. Electroceram., 2005, 14, 177-191.

42 X. Lv, J. Wu, D. Xiao, H. Tao, Y. Yuan, J. Zhu, X. Wang and X. Lou, Dalton Trans., 2015, 44, 4440-4448.

43 J. J. Zhou, K. Wang, F. Li, J. F. Li, X. W. Zhang, Q. M. Wang and S. Zhang, J. Am. Ceram. Soc., 2012, 96, 519-523.

44 X. Lv, J. Wu, S. Yang, D. Xiao and J. Zhu, ACS Appl. Mater. Interfaces, 2016, 8, 18943-18953.

45 S. Wada, Domain wall engineering in piezoelectric crystals with the engineered domain configuration, in Handbook of Advanced Dielectric, Piezoelectric and Ferroelectric MaterialsSynthesis, Characterization and Applications, ed. Z. G. Ye, Woodhead, Cambridge, England, 2008, pp. 266-303.

46 Y. Chang, S. Poterala, Z. Yang and G. L. Messing, J. Am. Ceram. Soc., 2011, 94, 2494-2498.

47 Z. Y. Shen, J. F. Li, K. Wang, S. Xu, W. Jiang and D. Deng, J. Am. Ceram. Soc., 2010, 93, 1378-1383.

48 K. Wang, F. Z. Yao, W. Jo, D. Gobeljic, V. V. Shvartsman, D. C. Lupascu, J. F. Li and J. Rödel, Adv. Funct. Mater., 2013, 23, 4079-4086. 